\section{Fall in fillings in Scotland}

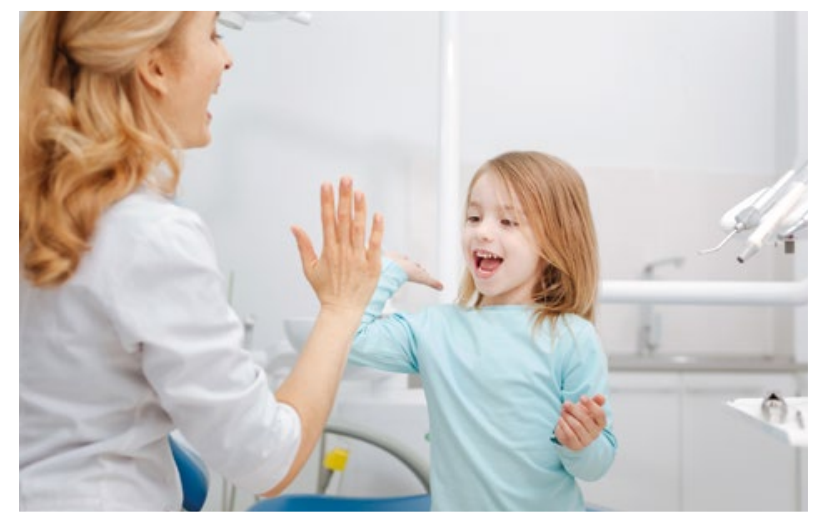

Programme Report

showed huge variation

in decay levels, with

the percentage of

Primary 1 children

free from dental decay

in the most deprived

areas 30 percentage

points worse than

in the least deprived

areas $(56 \%$ versus

$86 \%)$ - and the gap

actually increased by

The British Dental Association Scotland has welcomed further progress in the war on tooth decay, as new official stats show continued falls in the number of children with fillings and facing extractions.

Since 2000-01, the number of fillings given to children has reduced by $62 \%$ from 774,762 to 298,192 in 2018-19. Over the same period, the number of tooth extractions has fallen from 133,000 to $86,000-a$ decrease of $35 \%$.

BDA Scotland has been a longstanding supporter of the innovative Childsmile programme. It has, however, called on the Scottish Government to redouble its efforts, given the stark oral health inequalities across Scotland.

The last National Dental Inspection three percentage points from the previous report. In 2016, that gap had shown signs of narrowing.

Figures also show that the percentage of children free from dental decay in the most deprived areas (56\%) is still falling short of the Scottish Government's 2010 target of $60 \%$.

David McColl, Chair of the British Dental Association's Scottish Dental Practice Committee, said: 'Scotland is making real progress in the fight against tooth decay, but there is absolutely no room for complacency. The oral health gap between rich and poor is not inevitable. Ministers need to redouble their efforts to tackle these deep and persistent health inequalities'.

\section{BDA AGMs}

\section{Northern Ireland Branch AGM}

Tuesday 12 November 2019

Malone Lodge Hotel, 60 Eglantine

Avenue, Malone Road, Belfast, BT9

$6 \mathrm{DY}$

18:40 - 19:00 Northern Ireland

Branch AGM - all BDA members are encouraged to attend

19:00 - 19:20 Registration,

refreshments and exhibition

19:20 - 20:20 Lecture and Q\&A -

'How to get published and how the

BDJ Portfolio can help' with Stephen

Hancocks OBE and David Westgarth

To book visit www.bda.org/bse.

Apologies can be sent to laura.orr@

bda.org and will be recorded.

\section{Central Counties Branch AGM}

Wednesday 13 November 2019

Harborne Golf Club, 40 Tennal Road,

Birmingham, B32 2JE

18:30 Registration and refreshments

19:00 - 20:00 Central Counties

Branch AGM (all BDA members are encouraged to attend)

20:00 - 21:00 Lecture - 'The latest developments of the council and an overview of FtP process' with Clare Callan

To book visit www.bda.org/bse.

\title{
Welsh Government must not pinch pennies
}

The British Dental Association Wales has urged the Welsh Assembly Government not to rest on its laurels following the progress made by its Designed to Smile oral health programme, which celebrated its 10th birthday on 19 September.

While tooth decay in five-year-olds in Wales has declined by more than $10 \%$ since 2008, thanks in part to the programme, progress remains slow, and Welsh children's oral health still lags significantly behind their English counterparts. Dental decay is present in $35.4 \%$ of five-year olds in Wales.

BDA Wales has also expressed profound concerns that the current refocusing of Designed to Smile on under-5s has meant substantially redeploying a static budget away from older children. It understands several health boards have already stopped delivering fluoride varnish applications for 6-7-year-olds through the scheme. Many such children do not have the option of seeing a high street dentist - 33\% of children in Wales haven't seen a dentist in the last two years.

Dentist leaders have called for increased resources given the significant returns on investment these schemes generate through lower treatment costs, and for urgent action to address a mounting access crisis.

Lauren Harrhy, Deputy Chair of the BDA's Welsh General Dental Practice Committee said: 'Designed to Smile has made significant inroads, but the Welsh Government cannot rest on its laurels. This scheme shows

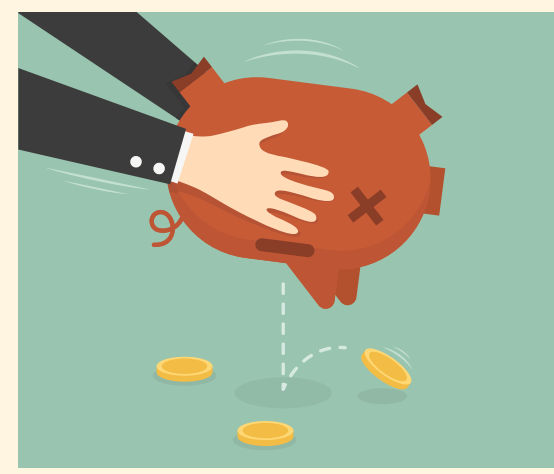

prevention works. We need real investment from Ministers not penny pinching, and a willingness to act on a crisis that's left barely a quarter of NHS practices taking on new child patients'. 